\title{
TCOM \\ Supporting quality in science communication: insights from the QUEST project
}

\section{Ilda Mannino, Laura Bell, Enrico Costa, Matteo Di Rosa, Alessandra Fornetti, Suzanne Franks, Claudia lasillo, Neil Maiden, Arko Olesk, Jacopo Pasotti, Berit Renser, Joseph Roche, Barbara Schofield, Roberta Villa and Fabiana Zollo}

\begin{abstract}
The promotion of quality is a critical aspect to consider in the re-examination of science communication. This problem is analysed in the research carried out by the QUEST project, as featured in this paper. Engaging key stakeholders in a codesign process - through interviews, focus groups, workshops and surveys - the research identified barriers to quality science communication and on the basis of these, proposes a series of tools and supporting material that can serve as incentives toward quality science communication for different stakeholders across the fields of journalism, social media, and museum communication. And it highlights in particular the significance of training in order to promote professionalism amongst communicators.
\end{abstract}

Keywords

Professionalism, professional development and training in science communication; Science and media; Science centres and museums

DOI

https://doi.org/10.22323/2.20030207

Submitted: 16th November 2020

Accepted: 31st January 2021

Published: 10th May 2021

Introduction

For decades, there have been efforts to increase and improve science communication. This has become especially pertinent in the time of a global pandemic when it is not only epidemiologists and virologists called upon to publicly communicate science, but also sociologists, economists, and policy-makers, alongside journalists and science communicators. The extent to which this communication is effective, clear and trustworthy, affects more people than ever around the world. QUEST (QUality and Effectiveness in Science and Technology communication) is a research project funded by the European Commission to tackle the issue of assessing and improving the quality of science communication (https:/ / questproject.eu/).

There is no doubt that the volume of science communication has increased over time, in particular when it comes to hot topics. Despite its increasing output, the 
question of how to ensure quality in science communication remains a critical consideration. Existing barriers and disincentives for science communication need to be identified as starting points to develop incentives for promoting science communication to wider publics. As highlighted by Davies et al. [2021], the diverse actors and media involved in the science communication ecosystem need to be given careful examination. The factors affecting quality in science communication start with scientists themselves, before passing through different communication channels to the public. The issues affecting how scientists communicate and the challenges facing different fields of communication such as journalism, social media, and museums are appraised below.

In recent decades, the different barriers that hinder quality in science communication have started to be identified. Firstly, focusing on scientists, it has been demonstrated that they are interested in, and recognise the value of, communicating outside academia to public audiences, but feel that such time consuming activity is not sufficiently recognised in career progression or funding awards [The Royal Society, 2006; Olson, 2018]. A survey of more than 6,000 U.S.-based scientists showed a significant appetite for science communication to help improve public trust in the scientific community, but with both personal confidence and institutional support being noted as potential barriers [Rose, Markowitz and Brossard, 2020].

Secondly, the media is also vulnerable to challenges affecting the quality of science communication. The literature reveals some of the sweeping changes in journalistic practice and consumption in recent years, with the advent of digital production, social media, web 2.0 and 3.0 [Angler, 2017]. These and other significant changes in the media landscape affect the ability of journalists to reliably report sound, evidence-based science news [Allan, 2011]. Davies et al. [2021] highlight issues that include the decreasing influence of traditional 'legacy media' alongside a well-developed public appetite for social media posts on science which are sometimes unintentionally misleading or deliberately manipulated to spread fake news and pseudoscience. A public inundated by mixed messaging and a range of interpretations is far less likely to develop trust in science messages in the media generally — leading potentially to disillusionment and disengagement among citizens. Meanwhile, science journalists report a daily bombardment of press releases and corporate communications whose branded content seeks to present a one-sided and favourable message [Bauer and Howard, 2009]. Still, the role of science journalists in society today, and their importance to democracy, is probably as critical as ever [Pfisterer, Paschke and Pasotti, 2019].

Thirdly, the Internet is rapidly becoming a primary source of information about scientific issues. Social media in particular have rapidly become the main information sources for many of their users, and the amount of information that competes for their attention is huge [Shearer and Grieco, 2019; Matsa et al., 2018]. On social media, users tend to segregate in echo chambers where people share similar backgrounds and ideas [Zollo et al., 2017]. Confrontation with opposing views is almost nonexistent, and scientists and communicators are too often guilty of hiding in their metaphorical ivory towers [Schmidt, Zollo, Del Vicario et al., 2017; Schmidt, Zollo, Scala et al., 2018]. In such a polarized context, the need to make science communication effective, avoiding the risk of preaching to the choir, is a key challenge. 
Finally, museums are cultural environments that can facilitate dialogue and the sharing of ideas around both science and art. One of the critical challenges facing museums is the need to be truly inclusive and engage disparate and diverse audiences. The science museum visionary Michael John Gorman stated that "interesting science is often created where boundaries are crossed, in border territories where connections are suddenly perceived between problems in seemingly unrelated areas" [Gorman, 2008, p. 522]. Just over a decade later and his message has become ever more pressing, as there is now a critical "need for civic spaces to function as dynamic, bidirectional bridges between science and society as colliders of ideas and people [...] this must be a central role of science museums of the present and future" [Gorman, 2020, p. 150]. Involving public audiences in participatory approaches, co-creation activities, and citizen science initiatives, will lead to citizens having a louder voice in the decision-making and governance of museums, and will strengthen the relationship between science and society [Rodari and Merzagora, 2007; Bandelli and Konijn, 2013; Sforzi et al., 2018]. The demand for ever improving science communication from the museum field grows more critical all the time: "In times of ecological collapse and global pandemics, it has never been more urgent to focus on reimagining our existing science museums and creating new edge spaces, to bring science-in-the-making into contact with policy, to bring research into contact with the public - the future of our planet depends on it" [Gorman, 2020, p. 153].

Starting from these challenges, QUEST has been working to identify the barriers to achieving quality in science communication, as perceived by stakeholders. The project subsequently developed tools to overcome these barriers, in order to support and promote high quality science communication. This paper shares the main outputs of the research undertaken during the QUEST project. The methodological approach is presented, followed by the obstacles and disincentives to achieving quality in science communication. The subsequent section presents a selection of tools, tailored to directly engage key stakeholders in how to overcome these obstacles.

In the final part of the paper, future directions and recommendations for all the decision-makers involved in promoting quality in science communication are discussed.

\section{Methodology}

The QUEST project is multidisciplinary by design; it is a collaborative project with eight partners from different fields of science communication across six European countries. The belief that practitioners of all disciplines, as well as policy-makers, and civil society, are equally important to achieving quality in science communication, is central to the project.

The methodology included a review of the existing literature on the promotion of quality in science communication [see Davies et al., 2021], an assessment of the provision for science communication education across Europe [see Costa et al., 2019], and initiated a series of activities that directly engaged key science communication stakeholders in co-design approaches to recognise the challenges they are facing, identify possible solutions, and develop tools to support quality in science communication. 
The co-designed activities involved online and in-person components, and between Spring 2019 and Autumn 2020 included: 62 structured and semi-structured interviews with experts, focus groups with 67 stakeholders (scientists, journalists and editors, museum explainers, social media content managers, university and research institute governance staff), multi-stakeholder workshops with 74 participants, and surveys (for a total of 139 answers collected). The stakeholders engaged were mainly from the 6 countries involved in QUEST project, i.e. Italy, France, Estonia, U.K., Ireland and Norway, but also from other EU and non-EU countries, e.g. Germany, The Netherlands, Belgium, Switzerland, Spain and African countries, reached through partner networks using convenience and snowball sampling. Support systems to make the online sessions interactive were put in place, using different platforms, such as padlet, survey monkey, and slack.

Quantitative and qualitative analysis of the data collected from the different activities identified the key challenges facing science communication, as perceived by stakeholders, and provided vital input for developing tools and solutions for promoting quality in science communication. The collection of stakeholder data represented the first phase of a three-step process. In the second step, the contributions from the stakeholders were further explored by the research team in a second round of discussions with both the same and different stakeholder groups. On the basis of the results from this second step, tools for supporting quality in science communication were developed, tested and validated with stakeholders. Non-European testing groups were also involved in the validation phase to make the tools implementable worldwide.

Quality in science communication: obstacles and disincentives

\section{Science communication obstacles and disincentives for scientists and research institutions}

Communicating science to public audiences is increasingly recognized as a responsibility of scientists [Greenwood and Riordan, 2001; Leshner, 2003], similarly, it is often stressed that researchers can play a role in supporting effective policy making [Pfisterer, Paschke and Pasotti, 2019]. In general, the third mission of universities and research institutions, to use their knowledge to engage with society and address its needs [García et al., 2012], is increasingly promoted. What encourages scientists to communicate their work? Which incentives and rewards do their organisations and media offer? Are scientists trained to deal with journalists and to engage with the public? Do they trust communication specialists hired by their institutions? These are the questions that frequently arise in science communication literature and which are at the basis of the investigation carried out by QUEST through a series of focus groups with scientists, interviews and surveys with the decision-makers, and other stakeholders at university and research institution level.

Although it is important for scientists to be able to communicate to non-technical audiences, researchers often either lack the skill or confidence to communicate to non-scientists. They are thoroughly trained in research methodologies, analytical skills, and the ability to communicate with other scientists, but they usually receive limited training in communication of scientific concepts to a general audience [Brownell, Price and Steinman, 2013], which is still considered in scientific academia to be a soft skill. This was confirmed by the scientists participating in QUEST activities. In addition, increased specialisation over time, research time 
pressure [Besley and Nisbet, 2011; Pearson, Pringle and Thomas, 1997], the lack of incentives, in terms of credits for career advancement, as well as being wary of the media each contribute to the current situation. Science communication to public audiences is then perceived by scientists as an extra effort that brings great satisfaction, but which is also very demanding in terms of time for preparation, as emerged in the QUEST focus groups.

Public information officers and science communicators 'embedded' in universities and in industry could be crucial in conveying scientific results to public audiences, through mediators (such as journalists, the media, and museums) or directly (through websites and social media), but, as highlighted by both researchers and communication officers engaged in QUEST co-design activities, more trust and stable interactions between scientists and these intermediaries is needed to build a more efficient and reliable exchange. The European Commission and its policies promoting open access publication, communication, and compulsory dissemination activities for the projects it funds also play an important role in this context. However, scientists participating in the QUEST project felt that there is more quantity in science communication than quality, and that qualitative indicators are needed in order to reverse this trend.

\section{Science communication obstacles and disincentives in journalism}

The media plays a crucial role in interpreting and framing scientific endeavour and research outputs to the public at large. When science reporting is trusted and deemed to be reliable, citizens can make well-informed decisions about science and its impact on their daily lives. In the era of pandemics and the devastating effects of climate change, trust in quality science journalism through the different media has never been more important, as evidenced by polls during 2020 [Open Knowledge Foundation, 2020]. Conversely, the effect of fake news and misinformation about scientific endeavour has never been more widespread than during the Coronavirus crisis. Surveys have pointed to an 'infodemic' of false claims and inaccurate data over this period [OFCOM, 2020]. As a result, it is clear that the role of science journalists in communicating reliable information has become more significant than ever.

However, the role of the science journalist is arguably more complex and more pressurised than that of other specialist reporters, since science itself is often done on the edge of the knowable, its findings open to misinterpretation, deliberate or inadvertent bias, and, occasionally, fraud [Goldacre, 2008]. That complexity sometimes generates barriers and obstacles to the clear and effective interpretation of scientific findings to the public; witness the current conflicting scientific and medical opinion about tackling the impact of COVID-19. Additionally, dwindling revenues for legacy media have meant news organisations are less likely to employ science specialists [de Semir, 2010]. General journalists handling science stories find themselves often lacking basic science literacy and the inability to properly interpret scientific data and statistics, especially given professional time constraints and the pressure of deadlines [Angler, 2017; Schünemann, 2012].

QUEST focused on three key scientific controversial topics: vaccination, climate change and artificial intelligence. In each case evidence was uncovered about the spread of distrust amid a climate of deliberate misinformation. 
Through direct contact with stakeholders and journalism practitioners the QUEST project discovered that training and tools supporting journalists, for example handling statistics and interpreting scientific papers, are particularly needed.

The interviews with practitioners demonstrated that science journalists are sometimes conflicted about their role; whether to act as a translator of often complex science, or to develop a more investigative slant as a 'watchdog', exposing bias, fraud or negligence. The process of interrogating claims, interpreting data and minimising uncertainty can be a lengthy one, again subject to the imperative of deadlines and editorial scheduling [Murcott and Williams, 2013; Schünemann, 2012]. As QUEST's mapping exercise revealed [Costa et al., 2019], science communication courses vastly outnumber specialist science journalism programmes in universities across Europe.

\section{Science communication obstacles and disincentives in museums}

The cloud of financial uncertainty looms large over every science museum or science centre, with funding for museums in decline even before the onset of the global economic recession of 2020 [Dorfman, 2017]. This uncertainty exacerbates the tension caused by museums accepting private or public funding (and subsequently declaring those sources), while the growing expectation of museums curating and sustaining a significant digital presence is a further challenge for professionals working in the museum sector. Underpinning these obstacles to improving science communication is the issue of inclusivity. This was the most pervasive issue that was raised by museum professionals taking part in QUEST interviews. Academic research conducted in nonformal learning spaces such as museums has shown for some time that museums and their programmes of exhibitions, events, and activities are not designed for everyone equally [Dawson, 2014]. The need for museums to be more inclusive and to finally extend "beyond a privileged subset of the population" has been highlighted by researchers as not just an obstacle to be overcome, but a matter of social justice that the museum sector urgently needs to address [Kinsley, 2016, p. 474].

Overcoming these barriers will not be easy and strong cooperation will be needed to navigate "the tough parts of change-making, to listen and understand visitors, to help set a direction informed by racialized and marginalized voices, and to establish ways of working together that are supportive, rooted in social justice, care, and consideration" [Ng, Ware and Greenberg, 2017, p. 151]. The pressing need to overcome these obstacles has only been amplified by the racial reckoning and the global pandemic that have affected almost every aspect of life in 2020 [Farhi and Ellison, 2020; Auðardóttir and Rúdólfsdóttir, 2020]. The position of museums in society as cultural spaces, academic spaces, safe spaces, and spaces of research, education, and entertainment, should not be taken for granted, and in the face of the current challenges, there are opportunities for positive change, as was repeatedly expressed by stakeholders in QUEST activities [Davies et al., 2021].

At the height of the first spate of national lockdowns in Europe, an examination of 100 of the largest Italian state museums showed that their engagement with public audiences did not cease during that period, but instead moved from physical interaction to digital activity, with the museums doubling their online engagement 
in that time [Agostino, Arnaboldi and Lampis, 2020]. While digital engagement is not always synonymous with accessibility, it is at least a path towards addressing some of the inequalities that museum visitors can experience [Kraybill, 2015]. Given the global events of 2020, there should be no further motivation needed to tackle these obstacles of accessibility. As Brown, Roche and Hurley [2020] suggest, the time is now for museums "to act and to commit [...] to providing the vital and relevant support that all peoples, including migrants and refugees, deserve [...] to act with humility and courage, to reform [...] and become cultural institutions which welcome, support, and value all communities" [p. 4].

\section{Science communication obstacles and disincentives in social media}

As we have heard from scholars, communicators and journalists engaged in surveys and workshops within the QUEST project, communicating science on social media is sometimes considered a more challenging task than using traditional media, such as books, conferences, even interviews in the press and on radio/TV. This is in part due to the fact that many experienced scientists, journalists, and communicators are less familiar with social networks because such platforms were not relevant or did not exist earlier in their careers, while younger professionals can face other kinds of constraint: using social media is in fact very time-consuming, without a clear and immediate reward, e.g. revenues or in academic acknowledgment.

Social media platforms are ever-changing and one needs to keep up to date and build skills. With some exceptions (LinkedIn, Twitter), social media are mainly seen as means of leisure, and the QUEST project found that some scientists may fear being criticized by colleagues and the public for using them. A further obstacle is around the role of 'opinion leader' on social media, which tends towards more of an influencer than a science advocate and communicator. A big hurdle, connected with the lack of reimbursement for this input, is the possibility of getting sponsors to support one's activity, and the possible conflict of interests deriving from this. Further problems arise concerning the specificities of most social networks, which require fast, short and simple messages, and therefore are not always consistent with the complexity of science or the communication needs of an institution.

Other peculiarities of social media make it difficult to communicate science through them. Empirical results show a strong polarisation in social media, dominated by selective exposure and users segregation in echo chambers [Del Vicario et al., 2016; Schmidt, Zollo, Del Vicario et al., 2017; Zollo et al., 2017; Zollo, 2019]. These dynamics may not help in science communication, which flourishes best when it engages different points of view in a civil exchange. On social media, reality is often depicted in black and white, false or true, while the idea of science as a growing process, gradually approaching reliable knowledge, is difficult to convey. People usually like, comment and share more with their gut than by rational thinking. Such emotional responses don't seem to be very consistent with a scientific method, and the potential for hate speech too is a further danger. Bullying and trolling are common on social media, and not everyone can feel equipped to deal with them as emerged in QUEST focus groups with scientists. All of these can be disincentives to the use of social media for science communication, especially by renowned scientists, science institutions and organizations, while young professionals can feel more confident if they have received adequate training. 
Last, but not least, there are obstacles related to the audience, which vary by country and platform [Davies et al., 2021]. Some platforms are used more by young people, others by middle-aged adults, and a gender gap can also be observed in some cases. Not all of these audiences have a background or a specific interest in science, as those who buy and read science magazines, watch or listen to science radio or TV programmes, or attend science festivals. On social media, anyone can stumble into a post or a tweet regarding science. This can be seen as an added value of these tools, since they allow communicators to reach out to people who may not have had a prior interest in science. On the other hand, this can be a challenge for communicators who engage audiences with no scientific background or interest, or even anti-science or hostile positions.

QUEST tools for supporting quality in science communication
Starting from the identification of the barriers and obstacles highlighted above, QUEST has been developing different tools and supporting material to address them, which can potentially work as incentives toward quality science communication.

\section{Addressing the need for quality indicators: the QUEST KPIs}

The ongoing pandemic has brought forward a renewed awareness of how important science communication is, and also how failures in communicating scientific studies or concepts can have harmful consequences for society [Saitz and Schwitzer, 2020]. Concerns about the quality of science communication and calls to improve it are nothing new, but, as mentioned above, they have increased with the widespread use of social media and the erosion of legacy media. "Contemporary information overload requires the user to be more competent, and it demands new definitions of quality", as noted by Bucchi and Trench [2014, p. 10]. Despite this, conceptualisations of quality in science communication are rare. In scholarly literature, the term is often associated with one or few key characteristics such as accuracy, objectivity, context, style, story-telling or engagement, but few have attempted to offer a holistic framework of quality components. These include Seethaler et al. [2019] who produced a set of ethics and values for effective science communication, and twelve core skills for effective science communication by Mercer-Mapstone and Kuchel [2017].

A framework of quality can be an effective tool in addressing the disincentives and obstacles previously described in this paper. It makes it easier to identify problematic science communication content and offer recommendations for improving it. It provides a basis for developing skills, including designing science communication programmes or courses. It also helps to create a common understanding of quality among science communication stakeholders, since a focus on different quality aspects by different stakeholders (e.g. journalists and researchers) is a frequent source of tension in science communication. Therefore, QUEST set out to develop Key Performance Indicators for quality in science communication. Consultation and co-design processes with science communication stakeholders produced a set of twelve quality indicators, arranged into three main dimensions of quality: trustworthiness and scientific rigour, presentation and style, and connection with the society [see Olesk et al., 2021]. 
The quality mapping exercise with stakeholders generated two key takeaway messages: a) different strands of science communication possess common underlying principles that make it possible to formulate a single framework of quality and use a common evaluation scheme on all forms of science communication; and b) quality should be considered as a multi-dimensional property that should be evaluated not by the presence or absence of a single quality element but by the combination of all elements. In this way, the quality framework QUEST is offering, contributes to a new view on science communication with both practical and theoretical implications. Our results seek to incentivise science communication by providing a set of guidelines based on the quality framework. These can also be used as a self-evaluation tool for people engaged in science communication. The quality indicators also offer a set of questions for further research about whether and how the perceived quality of science communication content translates into effective communication with the public. While journalists interviewed for QUEST expressed reservations about hard-and-fast guidelines in a profession already well-resourced with editorial codes and established ethical standards, there is every indication that the checklist drawn up within the project - on aspects of scientific rigour, presentation, and connection with the audience will provide support in particular to general journalists covering science topics, trainee journalists, and science journalism students. The scientists who validated the QUEST KPIs acknowledge that these can support their communication to the public, also through social media.

\section{Addressing the need for time and capacities in journalism: the INQUEST tool}

To enable journalists writing about science to overcome the reported barriers and obstacles to the clear and effective interpretation of scientific findings to the public, and to do this without requiring investment in more science journalists, the QUEST project designed and prototyped new forms of digital support for journalists, taking as its framework the three main dimensions of quality as presented in the KPIs, i.e. trustworthiness and scientific rigour, presentation and style, and connection with the society. This support was implemented in an interactive tool called INQUEST, which was co-designed with both experienced science journalists and less-experienced journalists seeking support to write about science.

The experienced science journalists reported using diverse sources of digital information for developing new stories about science-related topics, each with advantages and disadvantages. Therefore, to offset the disadvantages associated with each single type of source, design decisions were made to develop the INQUEST tool to discover information from multiple source types automatically, and to present this content to journalists who are writing new stories. These diverse sources included: science content available in published academic papers, reputable science blogs, and the science pages of established newspapers; non-science news content published in newspapers, to provide the wider context for science-related content; science news alerts such as EurekAlert!; and targeted social media sources such as the Twitter accounts of recognised scientists and research groups. INQUEST presents information and content from all of these sources in a common format, to stimulate journalist discovery and understanding.

Some of the experienced journalists reported writing for specific science journalism audiences. Therefore, the INQUEST tool was developed to present audience 
personas that represent a broader range of readers, their behaviours and their attitudes towards science, that journalists believe could be current and future audiences, when writing about science-related topics. A literature search revealed no existing audience personas for science journalism in the public domain, therefore existing research was identified to propose four important science audience segments: 'sciencephiles' with a strong interest in science, extensive knowledge and belief in its potential; the critically interested, also with strong support for science but with less trust in it; passive supporters with moderate levels of interest, trust, and knowledge; and disengaged people who are not interested in science, do not know much about it and harbour critical views toward it. Based on these segments, the INQUEST tool was implemented with a first set of 8 science audience personas based on the sciencephile (1 persona) critically interested (1) passive supporters (2) and disengaged (4) audience segments, specialized them to describe excluded audiences from the ethnic minorities and with lower incomes.

In response to the experienced science journalists' reports that explaining science was important, the design team investigated different theories that might support more effective explanation with different strategies. In the first version of the INQUEST tool, interactive explanation sparks were designed for different types of rhetorical relationship developed in narrative text. Each spark was designed to direct the journalist, and in particular less experienced ones, to think about new ways of explaining more entities extracted from existing papers, articles, stories and news alerts.

Likewise, the project's developing digital search and research tool, is designed to assist science journalists to reach more widely in both storytelling and connecting with audiences. [Maiden et al., 2020].

\section{Addressing the need for more capacity and skill in journalism: the QUEST curriculum on science journalism}

To address the imbalance between science communication courses and science journalism programmes [Costa et al., 2019], QUEST has developed a subject-specific curriculum combining the skills of rigorous investigation and of producing scientifically accurate reports on complex topics that are accessible to a lay audience.

In the era of enormous public concern about pandemics, a growing anti-vaccination movement, the devastating effects of climate change, and fear of AI, trust in quality science journalism through the different media has never been more important. As mentioned above, the effect of fake news and misinformation about scientific initiatives - often generated by unaccountable social media influencers - has never been more widespread and damaging [OFCOM, 2020]. With that in mind, there is a clear imperative to offer the next generation of journalists the opportunity and training to properly interrogate scientific findings and transmit evidence-based, accessible and engaging information to the public at large.

Evidence from QUEST's semi-structured workshops with journalists, editors and other stakeholders reveals that general journalists handling science stories find themselves often lacking basic science literacy and the inability to properly 
interpret scientific data and statistics, especially given professional time constraints and the pressure of deadlines. Specific modules have been developed, in consultation with working journalists, to address these shortcomings. Students will also study the module Science, Media and Society on the critical role played by scientific endeavour in supporting a well-functioning democracy.

The curriculum has been developed in parallel with QUEST's KPIs for quality and effective science communication, with the same emphasis on rigorously researched and engaging communication. Universities across Europe will be encouraged to adopt the curriculum or specific modules to enhance the effectiveness of science journalists and to boost professional recognition and public confidence.

\section{Addressing the need to improve inclusivity and academic credibility in museums: the QUEST Academic Writing Handbook for Museum Communicators}

The need to improve issues of inclusivity facing museums is not just a fundamental challenge for the museum sector but, as has been argued above, a matter of social justice. The obstacles and disincentives facing the museum sector are so endemic that reforms are needed at both national and international level in order to succeed. Policy-makers should be prioritising issues of diversity, equality, and inclusion, and museums themselves should have clear and publicly-accessible policies on social inclusion. The QUEST Academic Writing Handbook for Museum Communicators is a grassroots approach to empowering museum professionals to take ownership of the research in their field and to share their work in a more credible, robust, and far-reaching capacity in order to tackle issues of equality.

A crucial area of science communication that museum professionals are often excluded from is academic writing - the type of communication most often used for disseminating scholarship and research. While some museums are large enough to sustain a research department, most museums do not have the capacity to support their staff engaging in the evidence-based and peer-reviewed processes of academic writing and publishing. The QUEST Academic Writing Handbook addresses this by providing a resource that will encourage museum staff - especially educators and communicators working in museums, galleries, and science centres - to become more involved in how research from their field is written about and shared. The professional development of educators and communicators working in museums has been in need of support for some time [Bevan and Xanthoudaki, 2008] and the communication and education that takes place, in science museums especially, needs more clarity on best practice [Tran and King, 2007]. While there are limited opportunities for professional learning open to science communication professionals working in the museum sector [Roche et al., 2018], the most meaningful processes for professional development are likely to be the embedding of peer-learning through a co-creative and reflective practice approach within the museum itself [Moore et al., 2020].

If museum educators and communicators become more involved in academic writing they would have greater ownership over research outputs stemming from the museum sector. This could have the dual effects of strengthening the relationship between museum-based professionals and academic research, as well as bringing more creativity and professional communication standards to academic 
writing - a form of communication that is notoriously inaccessible to the public [Culler and Lamb, 2003]. Similarly, it would empower museum professionals to have more input into how their field is portrayed within the academic literature and how museum research is communicated to public audiences. Building up a community of practice and the development of skills in this area would increase the professionalism and credibility of museum-based communicators and educators. The QUEST Academic Writing Handbook is designed to address a pertinent question regarding theory and practice in science communication that was captured by an interviewee during the data collection stage of the QUEST project: "How is it that those who are doing science communication aren't reading the articles, and those who are writing the articles aren't doing any science communication?" [Davies et al., 2021].

Facing a lack of recognition and sometimes academic credibility for their work, the QUEST Academic Writing Handbook was itself designed by science communicators working in a museum environment. Using a co-creation process, the format and design of the handbook were chosen by those communicators to appeal to fellow museum professionals in the hope that the handbook might embolden them to write about their experiences in academic and professional journals and consequently add new dimensions to their own science communication skills.

Addressing the need for capacity in social media: tailored suggestions based on a data-driven approach

The Internet and social media are a big part of the information landscape. Undoubtedly, they represent a valuable channel for science communication, provided that they are used with purpose and that their own peculiarities are taken into account. Scientists, journalists, science communicators and practitioners may access a variety of material on the use of social media through workshops, courses, books, and articles [Lewis et al., 2018]. Most of this content is based on first-hand experience of their peers and colleagues. QUEST adopted a novel, data-driven approach to develop tailored recommendations for the use of social media in science communication. Our suggestions come from a thorough investigation of the activity of more than 1,000 social media accounts aiming to communicate and disseminate science [Davies et al., 2021], as well as from qualitative insights from literature review, surveys, and workshops organised throughout the QUEST project.

To ensure quality in science communication, our tips include specific recommendations grouped in three main conceptual areas, i.e. i) trustworthiness and scientific rigour, ii) presentation and style, and iii) impact on society. Along with recommendations to include references to the relevant scientific or official source(s) and to fact-check the content, we highlight the need of declaring conflicts of interest and considering gender and background balance, seeking a diversity of sources (e.g. in interviewees' selection). When communicating science, it is easy to yield to technical jargon. However, using narrative and storytelling is usually more appealing to the public, as well as including specific calls to action, e.g. asking questions, inviting to post and/or do something, organising flash mobs. In relation to the content of science communication, one should take care not only in terms of 
scientific rigour of what is communicated, but also of clarity and consistency among the different parts (e.g., between the title and the text). Particular attention should be devoted to ensure that the length and complexity of sentences, the wording, and the assumptions are tailored to one's target audience. As for the effectiveness, our suggestions can be summarised in what we called "the 3Ts" rule". We recommended our participants to always take into account 1) the Type of a tweet/post (post with only text, picture, video, link), 2) its Text (e.g., including hashtags or links), and 3) the Time when posting or tweeting during the day/week. Moreover, we provided specific suggestions to deal with controversial topics such as climate change, vaccines, and artificial intelligence. Our tips also include a checklist summarising all our suggestions in a more schematic way, to have it at hand when necessary. We do not expect that all the items in the checklist are achieved simultaneously, however our advice is to follow the 3Ts rule whenever possible, and to consider at least an element from the three aforementioned conceptual areas.

A first draft of our tips was field-tested with the direct help of 27 science communication accounts and their social media managers, that applied our tips to (some of) their tweets and/or Facebook posts for a five-month period. At the end of this experimental phase, we analysed the impact of our suggestions in terms of their adoption and effectiveness. Our preliminary results are very promising and show that Facebook posts and tweets following our tips achieved a significant higher median engagement than the others produced in the same period. This highlights the benefits that a data-driven, co-creating approach can provide to improve and foster science communication on social media.

\section{Addressing the need for increased capacities and skills: the QUEST toolkits}

QUEST research highlighted the need for specific capacities and skills for all stakeholders to achieve quality in science communication. What emerged from the QUEST mapping of the existing educational offerings in science communication is a fragmented European landscape [Costa et al., 2019]. Courses in science communication are present in almost every European country, but they are diverse in terms of context, target audience, and curricula. Most prepare science journalists and communicators for a wide scope of jobs, while few target scientists or Ph.D. students.

In light of this, QUEST has been developing a suite of tools that can support different stakeholders to ensure quality in science communication. These tools will be gathered in four toolkits, each one targeting different stakeholders: scientists, journalists, museum professionals, and social media content managers. The toolkits comprise the KPIs and the specific tools for journalism, museums and social media, listed above. Moreover, specific tips for each stakeholder are currently being developed and validated and will be provided in a graphic format to make them even more accessible to practitioners. These tips will also be included in PowerPoint presentations that can be used both by science communication trainers and directly by the target groups for self-directed learning.

A future development for the toolkits is the intention to produce a series of podcasts, with the purpose of adding specific focus, context and a human 
dimension to the range of deliverables. Working journalists attending a QUEST workshop had previously noted the difficulty of sourcing female scientists to contribute to their articles. The gender gap in science and technology has been well documented and attributed to an unsupportive culture within the scientific workforce [Cech and Blair-Loy, 2010]. To address this imbalance, and in recognition of the important role played by female scientists, researchers, science communicators and journalists, the majority of contributors and interviewees to the podcasts will be women. Focusing on specific scientific breakthroughs, a number of the podcasts will feature discussion between scientists keen to disseminate their findings and journalists tasked to report them in articles and broadcasts. In particular, they will explore how effective the communication between them proved to be, and crucially, how well served the general public ultimately were. Another will consider the media coverage of COVID-19, again reflecting on its effectiveness and identifying lessons learnt. A further podcast will shed light on the ways science galleries and museums are taking steps to diversify their visitor and audience profiles, and a final production will focus on the powerful role social media plays in the dissemination of scientific stories and research findings.

Incentivising quality in science communication at all levels:

preliminary insights from the QUEST policy recommendations
Policies play a key role in the promotion of more and better science communication, in order to overcome obstacles and challenges. QUEST policy recommendations will suggest strategies to be introduced by the decision-makers that have a role in the governance of science communication in the EU at the different levels, including policy makers at EU and national level, editors, governance bodies at research institutions and universities.

The most pressing issues and obstacles faced by the science communication ecosystem, highlighted in QUEST research are being analysed to be translated into a list of policy recommendations and incentives that will play a pivotal role in the promotion of better-quality science communication. Although their development is still ongoing, the QUEST Policy Recommendations will focus on suggesting I) existing good practices; II) practices that are not yet in place and could be created to overcome identified issues.

A combination of desk analysis and interviews with the main actors of the science communication ecosystem (i.e. journalists, scientists, policy makers, media industry, museums professionals, governance of research institutions from the public and the private sector, etc.) has been employed for this purpose, focusing on the needs and barriers of three different actors: researcher communicators (University/Research Organizations/Corporate Communication Officers, P.R. officers, etc.), scientific journalists and scientific museums.

Preliminary results of this ongoing analysis, aimed to investigate the framework conditions for incentivising quality science communication, are reported below.

For institutions focused on research, the QUEST policy recommendations highlight the need to reinforce the relationship and the trust between academia and the general public (science-society relationship) and to impact on the collaboration between researchers and communicators. To this aim, policy recommendation should revolve around the need to: 
- Increase the skill and competence in science communication fields of researchers and scientists, e.g. addressing the governance of RPOs to promote specific trainings also within science curricula

- Revise the role of communication officers and build a more efficient and reliable exchange between scientists and these intermediaries based on trust, e.g. by promoting exchanges and collaboration between them

- Establish networks and activities where science communication educators can meet, share best practice, and agree on key educational content would benefit the field and young science communicators

- Create a new set of competences and skills in field of public engagement in the RPOs

For the scientific journalists the QUEST policy recommendations focus on issues of misinformation, science complexity and the role of science journalists. To address these aspects, QUEST policy recommendations will provide suggestions on the need to:

- Improve science journalists' critical and evaluation capacities (watchdog role)

- Reward and acknowledge thorough science journalism

- Improve quality and effectiveness of services such as for example science media centres

- Reduce the conflicts, improve collaboration, mutual understanding and learning between journalists and scientists/communicators

For museums, the QUEST policy recommendations take into account the issue of inclusivity and the need for museums to be more equitable. QUEST final recommendations for the museum sector will consider the necessary steps to be undertaken and the actors to be involved in establishing Diversity, Equality, and Inclusion (DEI) policies within science museums.

The QUEST policy recommendations focus on tackling the issues of misinformation spread by social media, but also on nurturing the opportunities of a two dialogue with a wider audience and in a more timely manner than with other tools.

To do so, the QUEST policy recommendations will:

- Promote synergies among policy makers, researchers and platforms in order to combine transparency, freedom of speech, and accountability;

- Share and incentivise adoption of good practices (i.e. FB Data for Good);

- Investigate business models to shape a new role for journalists and popularizers on social media. 
In the last decades, increasing attention has been given to the quality of science communication and the challenges associated with it. The QUEST project tried to take a step forward, investigating these challenges, engaging directly with different science communication stakeholders and co-designing tools that can support them in implementing quality science communication. The issues of limited capacity and lack of time, as often reported by scientists, are tackled. Moreover, changes needed at the policy level have also been considered, targeting those that have decision-making roles, including policy-makers at national and European levels, as well as editors and university and research decision-making bodies.

Among other current barriers identified are the lack of expertise, of time and recognition, of indicators to evaluate the quality of science communication. Rapidly changing business models and diminishing newsroom resources are difficulties faced by journalists in combination with the rising power of public relations. For museums, the chronic underfunding of the arts and cultural sectors, coupled with a pressing need to tackle issues of social inclusion, are key aspects of the struggle to improve the quality of science communication. In the case of social media, the lack of competency and confidence in using these new channels, as well as the demand of time for their use without a clear and immediate reward (e.g., revenues, academic acknowledgment) are some of the key challenges. Moreover, the critical aspect of how to manage and limit polarisation in public discussions on social media has to be considered.

Starting from this array of evidence, QUEST has been developing a series of tools and supporting documents that can work as incentives towards ensuring quality in science communication. In particular, a set of key performance indicators were produced that have already been implemented as guiding principles for science communication; an AI tool to incentivise journalists in writing about science in a factual and engaging way has been developed for journalists looking for different angles to tell their stories; a curriculum for science journalism has been developed to be implemented by universities in order to fill the current educational gaps; and an academic writing handbook has been created to support museum communicators in sharing their expertise. Moreover, a set of tips, recommendations and guidelines for the different actors and media have been developed and will be part of specific toolkits for them.

As a final output of the project, recognizing the key role that policy can play in promoting quality science communication, policy recommendations for the different decision-makers are under development to ensure quality in science communication in journalism, social media, and museums.

Acknowledgments The authors would like to thank a number of people who contributed to data collection, including Margot Bezzi, Dr. Matteo Cinelli, Dr. Aaron Jensen, Dr. Ana Lucía Schmidt, as well as the wider QUEST team, whose knowledge and experience greatly benefited this work. We would also like to thank all the participants to the QUEST codesign and validation activities. This work would not have been possible without funding received from the European Union's Horizon 2020 research and innovation programme under grant agreement No 824634 . 
Agostino, D., Arnaboldi, M. and Lampis, A. (2020). 'Italian state museums during the COVID-19 crisis: from onsite closure to online openness'. Museum Management and Curatorship 35 (4), pp. 362-372. https://doi.org/10.1080/09647775.2020.1790029.

Allan, S. (2011). 'Introduction: Science journalism in a digital age'. Journalism 12 (7), pp. 771-777. https://doi.org/10.1177/1464884911412688.

Angler, M. W. (2017). Science journalism: an introduction. London, U.K.: Routledge.

Auðardóttir, A. M. and Rúdólfsdóttir, A. G. (2020). 'Chaos ruined the children's sleep, diet and behaviour: gendered discourses on family life in pandemic times'. Gender, Work E Organization. Early view. https://doi.org/10.1111/gwao.12519.

Bandelli, A. and Konijn, E. A. (2013). 'Science centers and public participation: methods, strategies, and barriers'. Science Communication 35 (4), pp. 419-448. https://doi.org/10.1177/1075547012458910.

Bauer, M. W. and Howard, S. (2009). The sense of crisis among science journalists. A survey conducted on the occasion of WCSJ_09 in London. URL: http://www . upf .edu/pcstacademy/_docs/SciJournalismBauer .pdf.

Besley, J. C. and Nisbet, M. (2011). 'How scientists view the public, the media and the political process'. Public Understanding of Science 22 (6), pp. 644-659. https://doi.org/10.1177/0963662511418743.

Bevan, B. and Xanthoudaki, M. (2008). 'Professional development for museum educators: unpinning the underpinnings'. Journal of Museum Education 33 (2), pp. 107-119. https://doi.org/10.1080/10598650.2008.11510592.

Brown, A., Roche, J. and Hurley, M. (2020). 'Engaging migrant and refugee communities in non-formal science learning spaces'. JCOM 19 (04), R01. https://doi.org/10.22323/2.19040601.

Brownell, S. E., Price, J. V. and Steinman, L. (2013). 'Science communication to the general public: why we need to teach undergraduate and graduate students this skill as part of their formal scientific training'. Journal of Undergraduate Neuroscience Education 12 (1), E6-E10.

Bucchi, M. and Trench, B. (2014). 'Science communication research: themes and challenges'. In: Routledge Handbook of Public Communication of Science and Technology. Ed. by M. Bucchi and B. Trench. 2nd ed. London, U.K. and New York, U.S.A.: Routledge, pp. 1-14. https ://doi .org/10.4324/9780203483794.

Cech, E. A. and Blair-Loy, M. (2010). 'Perceiving glass ceilings? Meritocratic versus structural explanations of gender inequality among women in science and technology'. Social Problems 57 (3), pp. 371-397. https://doi.org/10.1525/sp.2010.57.3.371.

Costa, E., Davies, S. R., Franks, S., Jensen, A., Villa, R., Wells, R. and Woods, R. (2019). D4.1: Science communication education and training across Europe. D4.1 EU H2020-funded 824634 QUEST Project.

URL: https://questproject.eu/download/deliverable-4-1-summary-report -science-communication-education-and-training-in-europe/.

Culler, J. D. and Lamb, K. (2003). Just being difficult? Academic writing in the public arena. Redwood City, CA, U.S.A.: Stanford University Press.

Davies, S. R., Franks, S., Roche, J., Schmidt, A. L., Wells, R. and Zollo, F. (2021). 'The landscape of European science communication'. JCOM 20 (03), 02. https://doi.org/10.22323/2.20030202.

Dawson, E. (2014). "'Not designed for us": how science museums and science centers socially exclude low-income, minority ethnic groups'. Science Education 98 (6), pp. 981-1008. https://doi.org/10.1002/sce.21133.

de Semir, V. (2010). 'Metareview: Science communication \& science journalism'. In: Media for Science Forum (Madrid, Spain, 12th-13th May 2010). 
Del Vicario, M., Bessi, A., Zollo, F., Petroni, F., Scala, A., Caldarelli, G., Stanley, H. E. and Quattrociocchi, W. (2016). 'The spreading of misinformation online'. Proceedings of the National Academy of Sciences 113 (3), pp. 554-559. https://doi.org/10.1073/pnas.1517441113.

Dorfman, E., ed. (2017). The future of natural history museums. London, U.K.: Routledge.

Farhi, P. and Ellison, S. (13th June 2020). 'Ignited by public protests, American newsrooms are having their own racial reckoning'. The Washington Post.

García, A. C., Carot, J. M., Soeiro, A., Hämäläinen, K., Boffo, S., Pausits, A., Murphy, M., Marhl, M., Vidal, J., Mora, J. G. and Padfield, C. (2012). Green paper. Fostering and measuring 'Third Mission' in higher education institutions. E3M Project. https://doi org/10.13140/RG.2.2.25015.11687.

Goldacre, B. (2008). Bad science. London, U.K.: Fourth Estate.

Gorman, M. J. (2008). 'Trinity says: let's talk'. Nature 451 (7178), p. 522. https://doi.org/10.1038/451522a.

- (2020). Idea colliders: the future of science museums. Cambridge, MA, U.S.A.: MIT Press.

Greenwood, M. R. C. and Riordan, D. G. (2001). 'Civic scientist/civic duty'. Science Communication 23 (1), pp. 28-40. https://doi.org/10.1177/1075547001023001003.

Kinsley, R. P. (2016). 'Inclusion in museums: a matter of social justice'. Museum Management and Curatorship 31 (5), pp. 474-490. https://doi.org/10.1080/09647775.2016.1211960.

Könneker, C., Niemann, P. and Böhmert, C. (30th January 2019). 'Young researchers and science communication: results of an extensive survey'. Lindau Nobel Laureate Meetings. URL: https://www . lindau-nobel.org/blog-young-research ers-and-science-communication/.

Kraybill, A. (2015). 'Going the distance: online learning and the museum'. Journal of Museum Education 40 (2), pp. 97-101. https://doi.org/10.1179/1059865015Z.00000000085.

Leshner, A. I. (2003). 'Public engagement with science'. Science 299 (5609), p. 977. https://doi.org/10.1126/science.299.5609.977.

Lewis, N. A., Van Bavel, J. J., Somerville, L. H. and Gruber, J. (2018). 'A social media survival guide for scientists'. Science. https://doi.org/10.1126/science.caredit.aav9607.

Maiden, N., Zachos, K., Franks, S., Wells, R. and Stallard, S. (2020). 'Designing digital content to support science journalism'. In: Proceedings of the 11th Nordic Conference on Human-Computer Interaction: Shaping Experiences, Shaping Society (Tallinn, Estonia, 25th-29th October 2020). https://doi.org/10.1145/3419249.3420124.

Massarani, L., Murphy, P. and Lamberts, R. (2020). 'COVID-19 and science communication: a JCOM special issue'. JCOM 19 (05), E. https://doi.org/10.22323/2.19050501.

Matsa, K. E., Silver, L., Shearer, E. and Walker, M. (2018). 'Western Europeans under 30 view news media less positively, rely more on digital platforms than older adults'. Pew Research Center Journalism E Media. URL: https : / /www . journalism . org/2018/10/30/western-europeans-under-30-view-news-media-less-pos itively-rely-more-on-digital-platforms-than-older-adults/.

Mercer-Mapstone, L. and Kuchel, L. (2017). 'Core skills for effective science communication: a teaching resource for undergraduate science education'. International Journal of Science Education, Part B 7 (2), pp. 181-201. https://doi.org/10.1080/21548455.2015.1113573. 
Moore, S., Roche, J., Bell, L. and Neenan, E. E. (2020). 'Supporting facilitators of maker activities through reflective practice'. Journal of Museum Education 45 (1), pp. 99-107. https://doi.org/10.1080/10598650.2019.1710688.

Murcott, T. H. L. and Williams, A. (2013). 'The challenges for science journalism in the U.K.' Progress in Physical Geography: Earth and Environment 37 (2), pp. 152-160. https://doi.org/10.1177/0309133312471285.

Ng, W., Ware, S. M. and Greenberg, A. (2017). 'Activating diversity and inclusion: a blueprint for museum educators as allies and change makers'. Journal of Museum Education 42 (2), pp. 142-154.

https://doi.org/10.1080/10598650.2017.1306664.

OFCOM (9th April 2020). 'Half of U.K. adults exposed to false claims about coronavirus'.

URL: https://www . of com.org.uk/about-of com/latest/features-and-news/h alf-of-uk-adults-exposed-to-false-claims-about-coronavirus.

Olesk, A., Renser, B., Bell, L., Fornetti, A., Franks, S., Mannino, I., Roche, J., Schmidt, A. L., Schofield, B., Villa, R. and Zollo, F. (2021). 'Quality indicators for science communication: results from a collaborative concept mapping exercise'. JCOM 20 (03), 08. https: //doi .org/10.22323/2.20030208.

Olson, S. (2018). 'Incentives in science communication'. In: The science of science communication III: inspiring novel collaborations and building capacity. Ed. by S. Olson. Washington DC, U.S.A.: The National Academies Press, pp. 31-40. https://doi.org/10.17226/24958.

Open Knowledge Foundation (7th May 2020). 'Opinion poll: majority of Brits want government action against online disinformation'.

URL: https://blog.okfn.org/2020/05/07/opinion-poll-majority-of-brits -want-government-action-against-online-disinformation/.

Pearson, G., Pringle, S. M. and Thomas, J. N. (1997). 'Scientists and the public understanding of science'. Public Understanding of Science 6 (3), pp. 279-289. https://doi.org/10.1088/0963-6625/6/3/006.

Pfisterer, A., Paschke, M. and Pasotti, J. (2019). Communicating science through the media. Ed. by M. Paschke and M. Dahinden. Engaging in the science-policy dialogue. Workbook 3. Zurich, Switzerland: Zurich-Basel Plant Science Center. https://doi.org/10.3929/ethz-b-000314920.

Roche, J., Davis, N., Stanley, J. and Hurley, M. (2018). 'The annual Ecsite conference: an engagement and education forum for science museums'. Journal of Museum Education 43 (1), pp. 78-82. https://doi.org/10.1080/10598650.2017.1407908.

Rodari, P. and Merzagora, M. (2007). 'The role of science centres and museums in the dialogue between science and society'. JCOM 06 (02), C01. https://doi.org/10.22323/2.06020301.

Rose, K. M., Markowitz, E. M. and Brossard, D. (2020). 'Scientists' incentives and attitudes toward public communication'. Proceedings of the National Academy of Sciences 117 (3), pp. 1274-1276. https://doi .org/10.1073/pnas. 1916740117.

Saitz, R. and Schwitzer, G. (2020). 'Communicating science in the time of a pandemic'. JAMA 324 (5), pp. 443-444. https://doi.org/10.1001/jama.2020.12535.

Schmidt, A. L., Zollo, F., Del Vicario, M., Bessi, A., Scala, A., Caldarelli, G., Stanley, H. E. and Quattrociocchi, W. (2017). 'Anatomy of news consumption on Facebook'. Proceedings of the National Academy of Sciences 114 (12), pp. 3035-3039. https://doi.org/10.1073/pnas.1617052114.

Schmidt, A. L., Zollo, F., Scala, A., Betsch, C. and Quattrociocchi, W. (2018). 'Polarization of the vaccination debate on Facebook'. Vaccine 36 (25), pp. 3606-3612. https://doi.org/10.1016/j.vaccine.2018.05.040. 
Schünemann, S. (2012). 'Science journalism'. In: Specialist journalism. Ed. by B. Turner and R. Orange. London, U.K.: Routledge, pp. 134-146.

Seethaler, S., Evans, J. H., Gere, C. and Rajagopalan, R. M. (2019). 'Science, values, and science communication: competencies for pushing beyond the deficit model'. Science Communication 41 (3), pp. 378-388. https://doi.org/10.1177/1075547019847484.

Sforzi, A., Tweddle, J., Vogel, J., Lois, G., Wägele, W., Lakeman-Fraser, P. and Makuch, Z. (2018). 'Citizen science and the role of natural history museums'. In: Citizen science. Innovation in open science, society and policy. Ed. by S. Hecker, M. Haklay, A. Bowser, Z. Makuch, J. Vogel and A. Bonn. London, U.K.: UCL Press, pp. 429-444. https ://doi .org/10.14324/111.9781787352339. URL: https://www.uclpress.co.uk/products/107613.

Shearer, E. and Grieco, E. (2nd October 2019). 'Americans are wary of the role social media sites play in delivering the news'. Pew Research Center Journalism $\mathcal{E}$ Media. URL: https://www . journalism. org/2019/10/02/americans-are-wary-of-the -role-social-media-sites-play-in-delivering-the-news/.

The Royal Society (2006). Science communication. Excellence in science. Survey of factors affecting science communication by scientists and engineers.

URL: https://royalsociety.org/topics-policy/publications/2006/scienc e-communication/.

Tran, L. U. and King, H. (2007). 'The professionalization of museum educators: the case in science museums'. Museum Management and Curatorship 22 (2), pp. 131-149. https://doi.org/10.1080/09647770701470328.

Zollo, F. (2019). 'Dealing with digital misinformation: a polarised context of narratives and tribes'. EFSA Journal 17 (S1), e170720. https://doi.org/10.2903/j. efsa.2019.e170720.

Zollo, F., Bessi, A., Del Vicario, M., Scala, A., Caldarelli, G., Shekhtman, L., Havlin, S. and Quattrociocchi, W. (2017). 'Debunking in a world of tribes'. PLoS ONE 12 (7), e0181821. https://doi .org/10.1371/journal . pone. 0181821.

Ilda Mannino, dr. in Environmental Sciences, is scientific coordinator of the TEN Program on Sustainability at the Venice International University. She teaches and carries out research on sustainable development issues, with a special focus on economy and policy and is scientific coordinator of the H2020 QUEST on science communication. She has a long experience in capacity building program for professionals and civil servants. E-mail: ilda.mannino@univiu.org.

Laura Bell is a research coordinator at the School of Education, Trinity College Dublin. She has experience working as an editor and project manager. She is a member of the Science \& Society research group at Trinity College where she manages a number of European research projects and coordinates the group's research output and publishing strategy. E-mail: laura.bell@tcd.ie.

Enrico Costa is a journalist and Media Relations coordinator at Ca' Foscari University of Venice. He graduated in Communication from the University of Trieste (Italy) and he has been working as a journalist, press officer, and communications manager since 2001. He organises the Ca' Foscari's Research Communication Week. He is a member of the Italian Association of Science Writers (Swim), the Italian Journalists Association, and of both European and Italian associations of HE communicators (Aicun and Euprio). E-mail: costa@unive.it. 
Matteo Di Rosa has a University degree in Natural Science at the University of Naples "Federico II" and a post-graduation master on Fundraising and Communication of Science at the University of Rome "La Sapienza". Matteo Di Rosa actually works in APRE as project manager and trainer with experience in dissemination and communication management, stakeholder engagement and community development, and over past years he has acquired expertise in the capacity-building field. E-mail: dirosa@apre.it.

Alessandra Fornetti is Executive Director of the TEN Program on Sustainability at the Venice International University (VIU), Italy. With a humanities background, she has been working for almost two decades in the field of sustainability developing international projects on education, communication and dissemination, to peers and the wide public, with experiences in China, East Europe and Central Asia. She coordinates H2020 QUEST on science communication and leads comm\&diss in MUHAI on Artificial Intelligence. E-mail: alessandra.fornetti@univiu.org.

Suzanne Franks is a former BBC TV broadcaster who is now Professor of Journalism at City, University of London. Her books include Africa's Media Image in the Twenty First Century and Reporting Disasters: Famine, Aid, Politics and the Media, Having None of it: Women, Men and the Future of Work and Women and Journalism. She leads a research project at City University on the role of women experts in the broadcast media and is a partner in the EU QUEST project. E-mail: suzanne.Franks.1@city.ac.uk.

Claudia Iasillo joined APRE in 2018. She holds a Ph.D. in Molecular Biology from Aarhus University, in collaboration with the French IGMM. She studied science communication at the post-graduation course at "La Sapienza", University of Rome, focusing on science journalism and institutional communication. In APRE she works as project manager on science and society relationship, science communication, citizen science, stakeholder and public engagement projects. She has been involved in several H2020 funded projects, i.e. RURITAGE, SISCODE, QUEST and FETFX. E-mail: iasillo@apre.it.

Neil Maiden is Professor of Digital Creativity at the Business School (formerly Cass) of City, University of London. His current research interests include uses of artificial intelligence to augment human creativity and enhancing design methods and tools to generate more creative solutions. E-mail: neil.Maiden.1@city.ac.uk.

Arko Olesk worked as a science journalist in Estonia's leading publications and received an MSc in science communication from Imperial College, London. Since 2013, he has been teaching science communication in Tallinn University, where his $\mathrm{Ph}$.D. project focuses on the mediatization of scientists. His other research interests include environmental communication and innovation communication. In the QUEST project, he led the work package for defining quality in science communication. E-mail: arko.olesk@tlu.ee.

Jacopo Pasotti is a journalist, photographer, reporter and editor, specialized in environmental reporting and science policies. He is a Science Communicator and lecturer, with ongoing cooperation at the Swiss Federal Institute of Technology; University of Zurich; RMIT, Melbourne; IIT, Genova; University Ca Foscari, Venice; IDM-YoungInside, South Tyrol's Technological Park. He is Communication and 
Media advisor at Venice International University and in H2020 QUEST project. E-mail: jacopo.pasotti@univiu.org.

Berit Renser (MA, University of Tallinn and University of Tartu) is a research assistant and a Ph.D. student of Audiovisual Arts and Media Studies at the Baltic Film, Media, Arts and Communication School of the University of Tallinn, Estonia. Her current research interests include social media, belief systems, and health and wellbeing. E-mail: beritren@tlu.ee.

Joseph Roche is an astrophysicist and Assistant Professor in Science Education at the School of Education and Science Gallery, Trinity College Dublin. He teaches undergraduate, masters, and doctoral level modules on "Science in Society" and "Communicating Science". His research interests include informal science education, citizen science, and evaluating public engagement in science.

E-mail: joseph.roche@tcd.ie.

Barbara Schofield worked as a journalist in BBC broadcast newsrooms and in production before moving into academic life at City, University of London. As lead consultant on the MediaPro initiative for the British Council, she drew up a modernising programme for journalism training in Vietnam. She was until recently Programme Director of Undergraduate Journalism at City, while also working on the Erasmus+ INSPIRE project to encourage inclusivity in higher education. She is currently Research Officer on the QUEST project at City University.

E-mail: B.Schofield@city.ac.uk.

Health journalist and science writer with a background in medicine, Roberta Villa is currently a research fellow involved in QUEST (Quality and Efficacy of Science Communication in Europe) at Ca' Foscari University in Venice. Previously, she had been working on EU-funded projects about preparedness and response to infectious threats, especially by communication and involvement of the public. In this field, she teaches Communication of epidemics at the Master in Science Communication "Franco Prattico" at SISSA (Trieste).

E-mail: robertaida.villa@unive.it.

Fabiana Zollo is an Assistant Professor (tenure track) at Ca' Foscari University of Venice, where she is PI of EU H2020 project QUEST on quality science communication, and of EU REC project IMSyPP on systems for monitoring and preventing online hate speech. She serves as an External Expert to EFSA, she is a member of the Task Force "Data Science" established by AGCOM, and of the Working Group established by the Italian Presidency of Council to investigate disinformation on COVID-19. E-mail: fabiana.zollo@unive.it.

How to cite

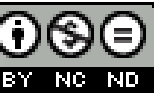

Mannino, I., Bell, L., Costa, E., Di Rosa, M., Fornetti, A., Franks, S., Iasillo, C., Maiden, N., Olesk, A., Pasotti, J., Renser, B., Roche, J., Schofield, B., Villa, R. and Zollo, F. (2021). 'Supporting quality in science communication: insights from the QUEST project'. JCOM 20 (03), A07. https:/ / doi.org/10.22323/2.20030207.

(C) The Author(s). This article is licensed under the terms of the Creative Commons Attribution - NonCommercial - NoDerivativeWorks 4.0 License. ISSN 1824-2049. Published by SISSA Medialab. jcom.sissa.it 